Article

\title{
Potential of Cellulose Microfibers for PHA and PLA Biopolymers Reinforcement
}

\author{
Gonzalo Mármol ${ }^{1, * \mathbb{D}}$, Christian Gauss ${ }^{2}$ and Raul Fangueiro ${ }^{1,3}$ (D) \\ 1 Centre for Textile Science and Technology (2C2T), University of Minho, 4800-058 Guimarães, Portugal; \\ rfangueiro@dem.uminho.pt \\ 2 School of Science and Engineering, University of Waikato, Hamilton 3216, New Zealand; \\ cgauss@waikato.ac.nz \\ 3 Department of Mechanical Engineering, University of Minho, 4800-058 Guimarães, Portugal \\ * Correspondence: gonzalomarmol@fibrenamics.com; Tel.: +351-917-798-754
}

Academic Editors: Pietro Russo and Sylvain Caillol

Received: 14 August 2020; Accepted: 7 October 2020; Published: 13 October 2020

check for updates

\begin{abstract}
Cellulose nanocrystals (CNC) have attracted the attention of many engineering fields and offered excellent mechanical and physical properties as polymer reinforcement. However, their application in composite products with high material demand is complex due to the current production costs. This work explores the use of cellulose microfibers (MF) obtained by a straightforward water dispersion of kraft paper to reinforce polyhydroxyalkanoate (PHA) and polylactic acid (PLA) films. To assess the influence of this type of filler material on the properties of biopolymers, films were cast and reinforced at different scales, with both CNC and MF separately, to compare their effectiveness. Regarding mechanical properties, $\mathrm{CNC}$ has a better reinforcing effect on the tensile strength of PLA samples, though up to $20 \mathrm{wt} . \%$ of MF may also lead to stronger PLA films. Moreover, PHA films reinforced with MF are $23 \%$ stronger than neat PHA samples. This gain in strength is accompanied by an increment of the stiffness of the material. Additionally, the addition of MF leads to an increase in the crystallinity of PHA that can be controlled by heat treatment followed by quenching. This change in the crystallinity of PHA affects the hygroscopicity of PHA samples, allowing the modification of the water barrier properties according to the required features. The addition of MF to both types of polymers also increases the surface roughness of the films, which may contribute to obtaining better interlaminar bonding in multi-layer composite applications. Due to the partial lignin content in MF from kraft paper, samples reinforced with MF present a UV blocking effect. Therefore, MF from kraft paper may be explored as a way to introduce high fiber concentrations (up to $20 \mathrm{wt} . \%$ ) from other sources of recycled paper into biocomposite manufacturing with economic and technical benefits.
\end{abstract}

Keywords: cellulose; biopolymers; multis-scale; microfibers; cellulose nanocrystals

\section{Introduction}

Composites are a dominant tool from a material science point of view as their properties facilitate the shape and form design while offering economic advantages for a wide variety of applications. Nevertheless, most of the synthetic petrol-derived composites introduce environmental disadvantages, of which their lack of biodegradability stands out. Plastic-based materials become worthless once they reach the end of their lifespan and, most of the time, these products end up in landfills with a subsequent environmental effect. Using a biobased or biodegradable polymer matrix to manufacture composite materials allows the obtainment of biodegradable products: green composites [1,2]. This technology leads to manufactured goods with a closed lifecycle, which may promote a circular economy. After green composites are discarded from their initial purpose, biogas production may be 
expected as fuel or feedstock for more biopolymer manufacture [3]. From the different biodegradable bioplastics, polylactic acid (PLA), polyhydroxyalkanoates (PHA), polycaprolactone (PCL), chitosan, starch, and cellulose can be highlighted. However, up to now PLA and PHA are the ones with a wider range of applications given their physicochemical and mechanical properties and reasonable price.

PLA is known as the utmost effective polymer for biomedical and packing composites, and it is the likely choice for the replacement of conventional plastics in a more sustainable way [4]. Nonetheless, other features such as fragility, reduced impact strength, and low thermal stability of PLA become a hurdle for the application of PLA in engineering purposes [5]. Likewise, PHAs are attracting attention as biodegradable alternatives for conventional polymers, and a significant effort has been made in this regard. On the other hand, PHAs are polyesters synthesized by numerous bacteria with remarkable properties for the next generation of environmentally friendly materials [6,7]. Medical and healthcare applications as cardiovascular tissue engineering, cartilage repair, ophthalmological transplantations, nerve regeneration, skin treatment, drug delivery systems, cell anchorage, amongst others are some of the most encouraging uses [6]. It is also possible to find alternative applications of PHA for commercial nonmedical purposes like packaging, fiber material, biofuels, a precursor of carbon material, paper finishing and nanoparticle stabilization amongst others [6]. However, the application of PHA for composite production is challenging due to the associated high cost of its production [8].

Another approach to reducing the composite materials' carbon footprint is the addition of other biodegradable components in their composition. In this regard, discrete natural fiber reinforcement (NFR) improves the sensitivity to temperature and mechanical performance of PLA, though it is difficult to obtain a homogenous mixture and good adhesion between matrix and fiber. Given the hydroxyl functional groups on the ends of natural fibers that confer them a hydrophilic behavior, there is a polarity variation between the fiber-matrix interface (Figure 1), contributing to their poor adhesion [9]. In the case of PHA matrices, limited mechanical improvement has been reported in the literature when cellulose-based fibers were used as reinforcement [10-12].
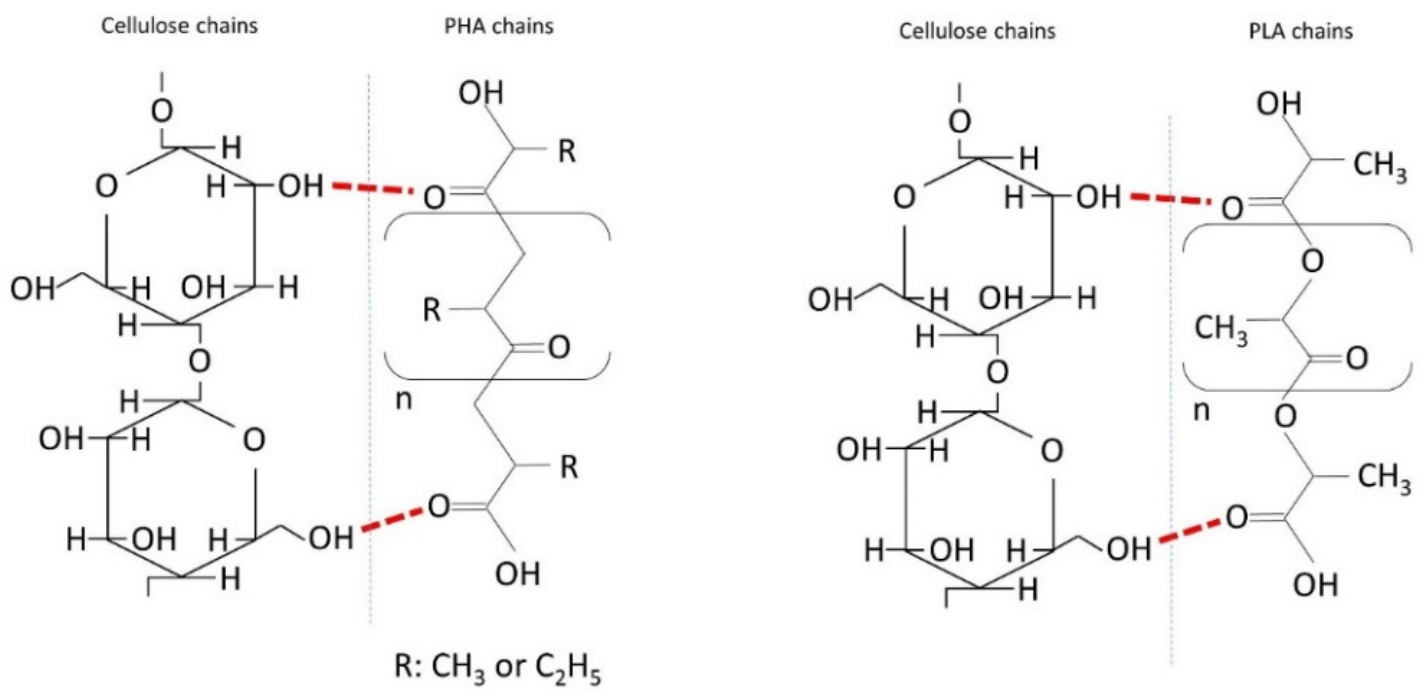

Figure 1. Schematic connection of polylactic acid (PLA) and polyhydroxyalkanoate (PHA) with cellulose.

Since the mechanical properties of composites are essential in material selection, a possible addition with reinforcing properties for both PLA and PHA matrices are cellulose nanoparticles. Several studies reported that the use of cellulose nanocrystals (CNC) in PLA matrices increased the tensile strength [13,14], whereas the addition of CNC in PHA leads to limited reinforcement [15,16]. Besides the improved mechanical properties of the PLA matrices, CNC exhibit singular structural features and excellent physicochemical properties such as biocompatibility, biodegradability, renewability, low density, adaptable surface chemistry, and optical transparency. 
However, an aspect that may hinder the addition of $\mathrm{CNC}$ in composite commodities is the current production process of this type of filler, which is energy-intensive [17]. Despite all the scientific advances to obtain CNC in a more sustainable way, currently, this type of filler is not suitable for large-scale industrial processes with a high demand for raw materials.

As an effortless solution to $\mathrm{CNC}$ addition, this work explores an innovative processing method to obtain natural fiber reinforcement (NFR) from kraft paper microfibers and their addition in polymeric matrices. The obtainment of this type of fibers is less energy demanding and requires low-tech equipment. Thus, a higher replacement of polymer by natural fibers of up to $30 \%$ by mass in composite matrices appears to be possible, bringing both economic and environmental advantages. On one hand, the use of microfibers (MF) from kraft pulp creates a path to incorporate recycled paper in composite manufacture, which increases sustainability and reduces production costs. On the other hand, microfibers (MF) may help to improve the adherence between the polymeric matrix and the natural fiber reinforcement used in later stages for the manufacture of multi-layer green composites, combining several layers of staked biopolymers and natural mats. For that, the production of thin films made out of PLA and PHA will incorporate CNC and MF separately as fillers to assess their comparative tensile strength and microstructural properties.

\section{Materials and Methods}

\subsection{Materials}

Polylactic acid (PLA) Ingeo 4043D was kindly provided by NatureWorks ${ }^{\circledR}$ with an Melt Flow Rate $=6 \mathrm{~g} / 10 \mathrm{~min}$ at $10^{\circ} \mathrm{C}$, specific gravity of $1.24 \mathrm{~g} / \mathrm{cm}^{3}$, and peak melt temperature between $145^{\circ} \mathrm{C}$ and $160^{\circ} \mathrm{C}$. Polyhydroxyalkanoate (PHA) was supplied by Goodfellow Cambridge, MFR = $3 \mathrm{~g} / 10 \mathrm{~min}$ at $170{ }^{\circ} \mathrm{C}$, specific gravity of $1.24 \mathrm{~g} / \mathrm{cm}^{3}$ and peak melt temperature between $140{ }^{\circ} \mathrm{C}$ and $160{ }^{\circ} \mathrm{C}$. $\mathrm{CNC}$ with an average particle size of $75 \mathrm{~nm}$ was purchased from Celluforce (Montreal, QC, Canada), in spray-dried form. The paper kraft used in this study is made from commercial Tunisian Alfa bleached Stipa tenacissasima. The morphological parameters determined by Morfi apparatus are an average length weighted in length $=841 \mu \mathrm{m}$, average width $=16.7 \mu \mathrm{m}$, coarseness $=0.073 \mathrm{mg} / \mathrm{m}$, average kink number $=1.253$, average angle $=130.8^{\circ}$, kinked fibers $=29.3 \%$ and average curl $=8.15 \%$. Reagent grade chloroform $\left(\mathrm{CHCl}_{3}\right)$ with 99\% purity was purchase from Honeywell, CAS: 67-66-3, with a density value of $1.48 \mathrm{~g} / \mathrm{cm}^{3}\left(20^{\circ} \mathrm{C}\right)$ and vapor pressure of $210 \mathrm{hPa}\left(25^{\circ} \mathrm{C}\right)$.

\subsection{Sample Production}

The method to obtain MF from kraft paper started with a shredding process of the kraft until particles of around $20 \mathrm{~cm}^{2}$ were obtained. Then paper particles were immersed in water for $48 \mathrm{~h}$. After long water immersion, mechanical stirring was applied for $1 \mathrm{~h}$ for paper disintegration. The paper suspension in water was drained and oven-dried at $105^{\circ} \mathrm{C}$ until it reached constant weight. To deagglomerate MF clusters, polymer pellets were added to the correspondent amount of $\mathrm{MF}$ according to the different formulations (Table 1) and placed in a blender machine for mechanical abrasion between MF and polymer particles.

\subsubsection{CNC-Filled Samples}

For CNC samples, first $10 \mathrm{~mL}$ of $\mathrm{CNC}$ suspensions in $\mathrm{CHCl}_{3}$ were placed in centrifuge tubes for CNC deagglomeration by mechanical vibration for $10 \mathrm{~min}$ using a vortex shaker IKA VORTEX 3. Then, suspensions were diluted by adding $\mathrm{CHCl}_{3}$ to obtain a total volume of $50 \mathrm{~mL}$ and suspension stabilization was carried out by ultrasonic treatment for $5 \mathrm{~min}$, so proper dispersion and distribution of the fibers in $\mathrm{CHCl}_{3}$ was assured. 


\subsubsection{MF-Filled Samples}

For MF samples, the right fiber dispersion was obtained by high shear mixing using a co-rotating twin-screw extruder Microlab, Rondol ${ }^{\circledR}$. PLA and MF were blended using a temperature profile of $145^{\circ} \mathrm{C}-200{ }^{\circ} \mathrm{C}-200{ }^{\circ} \mathrm{C}-195^{\circ} \mathrm{C}-190^{\circ} \mathrm{C}$ (feed to die) and a rotation speed of $55 \mathrm{rpm}$, while PHA and MF were blended with a temperature profile of $130{ }^{\circ} \mathrm{C}-145^{\circ} \mathrm{C}-150{ }^{\circ} \mathrm{C}-150{ }^{\circ} \mathrm{C}-140{ }^{\circ} \mathrm{C}$ at a rotation speed of $65 \mathrm{rpm}$. Later MF-polymer blends were chopped until pellet homogenization.

For every film production (both CNC-filled and MF-filled samples), $2.84 \mathrm{~g}$ of polymer was added to $50 \mathrm{~mL}$ of $\mathrm{CHCl}_{3}$ (suspension in the case of $\mathrm{CNC}$ samples) for its dissolution with the aid of magnetic stirring for $1 \mathrm{~h}$ at $60^{\circ} \mathrm{C}$ and $1 \mathrm{~h}$ cooling down at room temperature. Film casting took place in ceramic trays to promote solvent evaporation at ventilated room conditions. In all the cases, solvent-cast films with a thickness between 0.15 and $0.2 \mathrm{~mm}$ were obtained.

Table 1. Formulations of the different films assessed.

\begin{tabular}{cccc}
\hline & Polymer & Filler Type & Content (wt.\%) \\
\hline PHA & PHA & None & 0 \\
PHA + $\%$ CNC & PHA & CNC & 1 \\
PHA + $\%$ CNC & PHA & CNC & 2 \\
PHA + 3\% CNC & PHA & CNC & 3 \\
PHA + 10\% MF & PHA & MF & 10 \\
PHA + 20\% MF & PHA & MF & 20 \\
PHA + 30\% MF & PHA & MF & 30 \\
PLA & PLA & None & 0 \\
PLA + 1\% CNC & PLA & CNC & 1 \\
PLA + 2\% CNC & PLA & CNC & 2 \\
PLA + 3\% CNC & PLA & CNC & 3 \\
PLA + 10\% MF & PLA & MF & 10 \\
PLA + 20\% MF & PLA & MF & 20 \\
PLA + 30\% MF & PLA & MF & 30 \\
\hline
\end{tabular}

Sample preparation for each type of filler used, either cellulose nanocrystals (CNC) or microfibers (MF), followed different routes.

\subsection{Sample Testing}

Tensile testing was conducted following the ASTM D882-02 standard. A total of 5 specimens for each formulation were cut into $100 \times 10 \mathrm{~mm}$ strips and tested at a crosshead displacement of $5 \mathrm{~mm} / \mathrm{min}$ in a universal testing machine (Hounsfield Tinius Olsen, model H100 KPS) equipped with a load cell of $2.5 \mathrm{kN}$. The averages of tensile strength, elongation at break and Young's modulus for each composite formulation are presented with the corresponding coefficient of variation (COV). The differences among the treatment conditions on the evaluated properties were checked by a Tukey test and analysis of variance (ANOVA) for significant $(p<0.05)$ differences. All analyses were performed using MINITAB Release 18 Statistical Software.

Differential scanning calorimetry (DSC) analyses were carried out in a covered aluminum crucible under a nitrogen flow of $100 \mathrm{~mL} / \mathrm{min}$ in a Metler Toledo, $\left(822^{\mathrm{e}}\right)$ differential scanning calorimeter following the ASTM D3418 standard. Samples were heated from room temperature to $200{ }^{\circ} \mathrm{C}$ at a heating rate of $10^{\circ} \mathrm{C} / \mathrm{min}$ and cooled down at a rate of $10{ }^{\circ} \mathrm{C} / \mathrm{min}$ down to $30^{\circ} \mathrm{C}$ to determine the transition temperature $\left(\mathrm{T}_{\mathrm{g}}\right)$, melting temperature $\left(\mathrm{T}_{\mathrm{m}}\right)$, cold crystallization temperature $\left(T_{c c}\right)$ and, therefore, calculate the heat of fusion and degree of crystallinity of the samples $\left(X_{c}\right)$. Degree of crystallinity $\left(X_{c}\right)$ was calculated according to [18]:

$$
X_{c}(\%)=\frac{\Delta H_{m}}{W \times \Delta H_{\text {polymer }}} \times 100
$$


where $\Delta H_{m}$ is the melting enthalpy of the samples. $\Delta H_{\text {polymer }}$ is the enthalpy for $100 \%$ crystalline PLA and PHA, which is approximately $93.6 \mathrm{~J} / \mathrm{g}$ and $146 \mathrm{~J} / \mathrm{g}$, respectively, $[18,19]$ and $W$ is the net weight fraction of PLA or PHA in the composites. The enthalpy values were evaluated as the integral of their corresponding peak, i.e., the area under the endothermic peak to estimate the melting enthalpy.

Thermogravimetric analysis was performed using a thermal analyzer (HITACHI STA 7200). Dried samples were introduced in alumina crucibles and were heated from $20^{\circ} \mathrm{C}$ to $400^{\circ} \mathrm{C}$ at $10^{\circ} \mathrm{C} / \mathrm{min}$ under nitrogen flow at $40 \mathrm{~mL} / \mathrm{min}$.

Infrared spectra of the films were performed on a Shimadzu, IRAffinity-1S Bruker Fourier Transform Infrared Spectrophotometer using an attenuated total reflectance (ATR) module. Transmittance spectra were registered between 400 and $4000 \mathrm{~cm}^{-1}$, with a resolution of $4 \mathrm{~cm}^{-1}$ and 45 scans.

Microscopic analysis was conducted by optical microscopy, scanning electron microscopy (SEM) and atomic force microscopy (AFM). The surface of the films was assessed by an optical microscope using a Leica DM750M at 50× and 100× magnification. Microfiber length and width, as well as the apparent pore size of the films, were determined for every film formulation by averaging 100 image measurements with the aid of ImageJ software. Morphological analyses were realized in an Ultra-high-resolution Field Emission Gun Scanning Electron Microscopy (FEG-SEM), NOVA 200 Nano SEM, FEI Company. Topographic images were obtained with a secondary electron detector at an acceleration voltage of $10 \mathrm{kV}$. Before morphological analyses, samples were coated with a thin film $(8 \mathrm{~nm})$ of Au-Pd (80-20 weight \%), in a high-resolution sputter coater, 208HR Cressington Company, coupled to an MTM-20 Cressington high-resolution Thickness Controller.

The morphological analyses were performed by Scanning Atomic Force Microscopy, using a Nanoscope III Multimode Atomic Force Microscope, from Digital Instruments, where images of $5 \times 5 \mu \mathrm{m}^{2}$ and $10 \times 10 \mu \mathrm{m}^{2}$ were acquired on the surface of all samples. The scanning mode used was intermittent contact or tapping mode, in air, with a cantilever whose spring constant is $42 \mathrm{~N} / \mathrm{m}$ and the resonance frequency was approximately $310 \mathrm{kHz}$, determining the surface roughness of the films.

The contact angle was determined after $15 \mathrm{~s}$ of the contact of the drop of water with the surface of the film using a Dataphysics OCA Contact Angle System.

The light transmittance of the film samples was determined using a UV-visible spectrophotometer (UV/Vis spectrophotometer), UV-2600 Shimadzu in the wavelength of 200-600 nm. The transmittance at $600 \mathrm{~nm}\left(\mathrm{~T}_{600}\right)$ and $300 \mathrm{~nm}\left(\mathrm{~T}_{300}\right)$ was used to evaluate the transparency and UV barrier property of the films, respectively.

\section{Results and Discussion}

The results obtained by the mechanical, physical, and thermal analyses are summarized in Tables 2 and 3 and discussed in the next sections.

\subsection{Tensile Tests}

Samples were tested under tensile configuration to obtain the mechanical properties of the different composite formulations. Figure 2 displays the values of tensile strength and elongation at ultimate strength. Comparing the tensile strength values of both neat PLA and PHA samples, PLA exhibits higher values (52.3 MPa) compared to PHA (20.2 MPa). These values are in accordance with the results reported in the literature $[20,21]$. When CNCs are added to both types of matrices, tensile strength increases for every formulation. The greater improvement in tensile strength is most noticeable in PLA samples, where a maximum increase of up to $38 \%$ was achieved for $1 \%$ CNC PLA samples, with no evident effect on the elongation at break. In fact, all the PLA formulations reinforced with CNC presented statistically equivalent elongation at break values (Table 2). Regarding PHA samples, for every CNC addition content, a lower tensile strength enhancement (approximately $10 \%$ ) is observed compared to PLA films. However, the elongation at break is considerably improved, especially the $1 \%$ CNC PHA formulation with an increase of approximately $130 \%$. 
Table 2. Mechanical properties PLA and PHA composites with different reinforcing fillers (CNC and $\mathrm{MF})$. Same letters $(a, b$, or $c)$ mean there is no statistical difference among the composites with the same matrix.

\begin{tabular}{|c|c|c|c|c|c|c|}
\hline \multirow{2}{*}{$n=5$} & \multicolumn{2}{|c|}{ Tensile Strength (MPa) } & \multicolumn{2}{|c|}{ Elongation at Break (\%) } & \multicolumn{2}{|c|}{ Young's Modulus (GPa) } \\
\hline & Avr. & $\mathrm{COV}$ & Avr. & $\mathrm{COV}$ & Avr. & $\mathrm{COV}$ \\
\hline PHA & $20.2^{c}$ & 0.07 & $4.47^{\mathrm{b}}$ & 0.06 & $0.54^{\mathrm{c}}$ & 0.12 \\
\hline $\mathrm{PHA}+1 \% \mathrm{CNC}$ & $22.5^{a, b, c}$ & 0.02 & $10.43^{\mathrm{a}}$ & 0.23 & $0.72^{b}$ & 0.02 \\
\hline $\mathrm{PHA}+2 \% \mathrm{CNC}$ & $22.6^{\mathrm{a}, \mathrm{b}, \mathrm{c}}$ & 0.06 & $5.85^{b}$ & 0.13 & $0.81^{\mathrm{a}, \mathrm{b}}$ & 0.06 \\
\hline $\mathrm{PHA}+3 \% \mathrm{CNC}$ & $22.2^{b, c}$ & 0.03 & $5.95^{b}$ & 0.25 & $0.81^{\mathrm{a}, \mathrm{b}}$ & 0.05 \\
\hline $\mathrm{PHA}+10 \% \mathrm{MF}$ & $23.5^{\mathrm{a}, \mathrm{b}}$ & 0.03 & $4.33^{b}$ & 0.10 & $0.81^{\mathrm{a}, \mathrm{b}}$ & 0.03 \\
\hline $\mathrm{PHA}+20 \% \mathrm{MF}$ & $24.9^{\mathrm{a}}$ & 0.05 & $3.78^{b}$ & 0.11 & $0.94^{\mathrm{a}}$ & 0.14 \\
\hline $\mathrm{PHA}+30 \% \mathrm{MF}$ & $23.0^{a, b}$ & 0.06 & $3.93^{\mathrm{b}}$ & 0.04 & $0.93^{\mathrm{a}}$ & 0.06 \\
\hline PLA & $52.3^{b, c}$ & 0.02 & $3.86^{\mathrm{a}}$ & 0.13 & $1.95^{b, c}$ & 0.05 \\
\hline PLA $+1 \%$ CNC & $72.9^{a}$ & 0.05 & $4.02^{\mathrm{a}}$ & 0.12 & $2.12^{a, b, c}$ & 0.07 \\
\hline $\mathrm{PLA}+2 \% \mathrm{CNC}$ & $68.6^{\mathrm{a}}$ & 0.06 & $3.51^{\mathrm{a}}$ & 0.10 & $2.05^{a, b, c}$ & 0.03 \\
\hline $\mathrm{PLA}+3 \% \mathrm{CNC}$ & $65.5^{\mathrm{a}}$ & 0.06 & $3.54^{\mathrm{a}}$ & 0.13 & $1.92^{\mathrm{C}}$ & 0.03 \\
\hline PLA + 10\% MF & $55.2^{b}$ & 0.02 & $2.00^{b}$ & 0.16 & $2.28^{a, b}$ & 0.10 \\
\hline PLA + 20\% MF & $65.2^{\mathrm{a}}$ & 0.05 & $3.38^{\mathrm{a}}$ & 0.04 & $2.39^{a}$ & 0.09 \\
\hline PLA + 30\% MF & $47.0^{\mathrm{c}}$ & 0.12 & $2.37^{\mathrm{b}}$ & 0.12 & $2.36^{\mathrm{a}}$ & 0.07 \\
\hline MF & \multirow{2}{*}{\multicolumn{3}{|c|}{ Fiber length }} & \multirow{2}{*}{\multicolumn{3}{|c|}{$841 \pm 71 \mu \mathrm{m}$}} \\
\hline $\mathrm{CNC}$ & & & & & & \\
\hline
\end{tabular}

Table 3. Summary of results obtained by physical characterization of PLA and PHA composites with different reinforcing fillers (CNC and MF). Different letter between treatments means a significant statistical difference $(p>0.05)$.

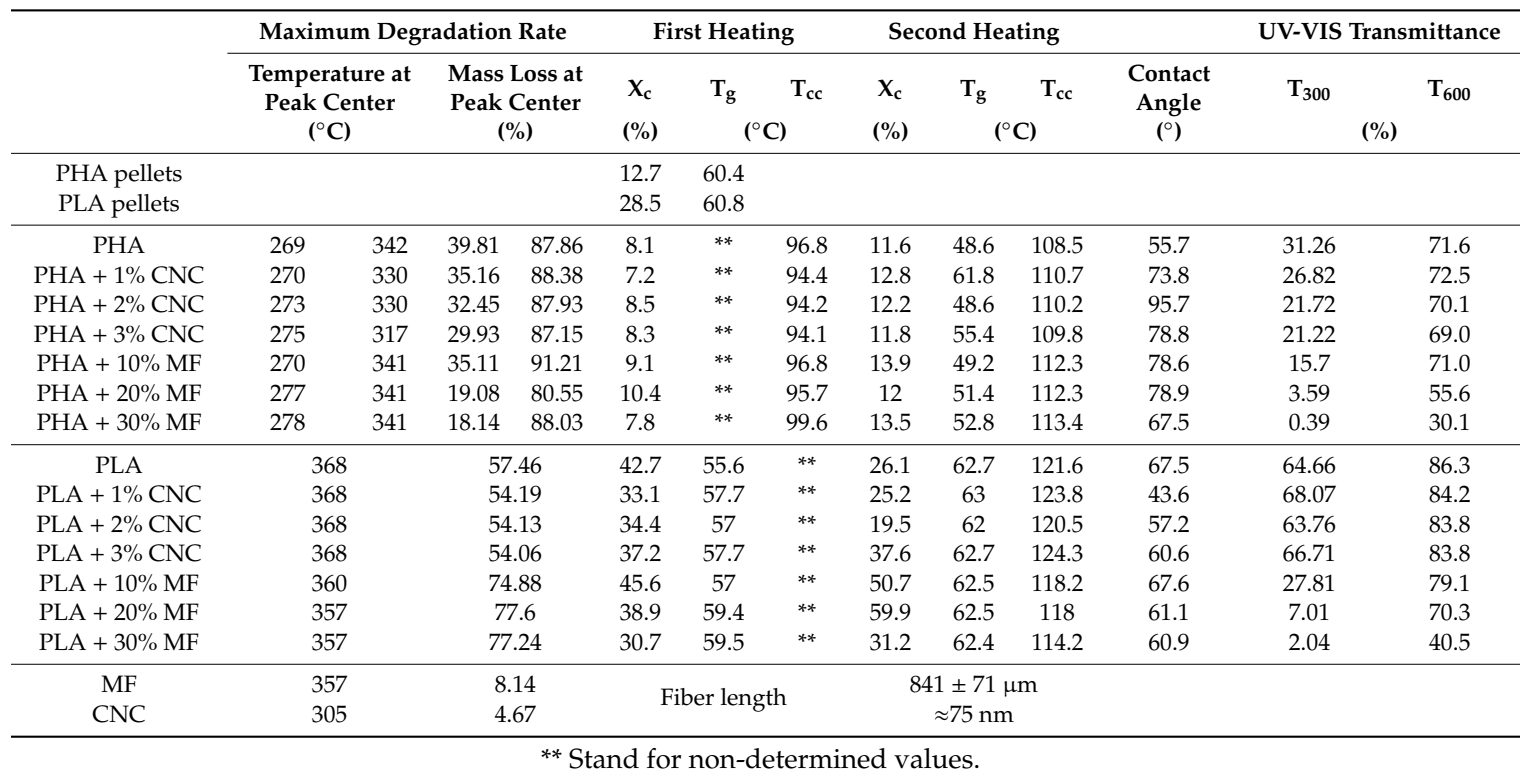

Regarding the use of MF as filler, PLA samples have lower tensile strength compared to PLA containing CNC. Samples with $30 \%$ by mass of MF show a decrease in tensile strength. However, tensile strength improves by around $25 \%$ with preservation of the elongation at ultimate strength in the $20 \%$ MF-PLA samples. Therefore, the specific energy absorbed by $20 \%$ MF-PLA samples increases under tensile loading. In comparison with samples with $\mathrm{CNC}$, tensile strength improves even more for MF-PHA composites, with an increase between 14 and 23\%, where the highest value is obtained by the $20 \%$ MF samples. Nevertheless, this increase in tensile strength is accompanied by a reduction of the elongation at ultimate strength. 


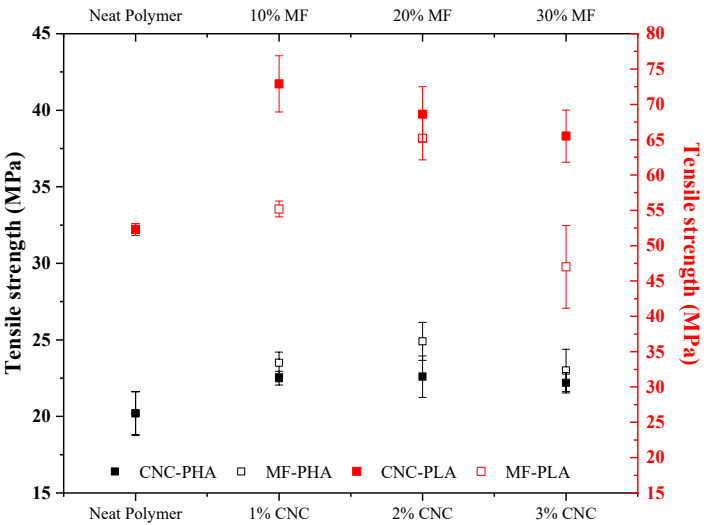

(a)

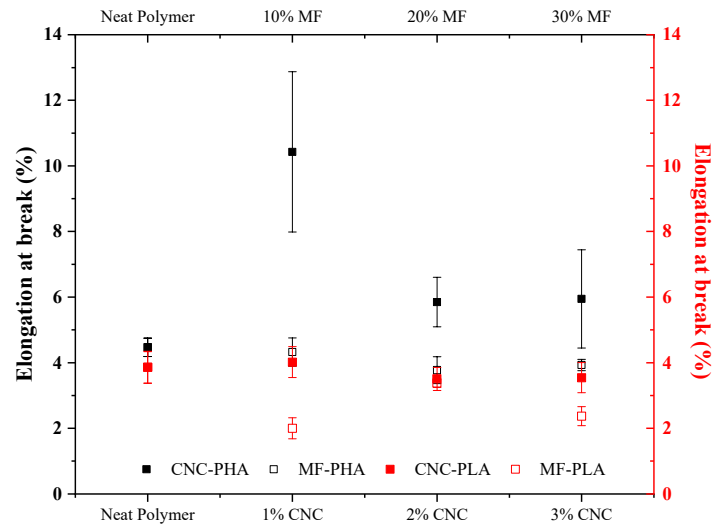

(b)

Figure 2. Tensile strength (a) and elongation at break (b) of PHA and PLA films reinforced with CNC and MF with varying the filler ratios. Error bars indicate one standard deviation in all cases.

Some studies indicate that the addition of fibers to non-polar thermoplastics reduces the tensile strength due to the poor fiber-matrix adhesion at the interface, which is related to low interfacial stress transfer [22]. In order to improve the reinforcing effect of the fibers in these polymers, coupling agents are used to increase the compatibility between the fibers and the matrix [3]. However, in this work, MF addition (without a coupling agent) led to enhancements in both tensile modulus and strength, showing affinity between the MF and the polymers used here (PLA and PHA). Consistent with these findings, previous studies using PHA composites reinforced with agave fibers presented identical results, where the tensile modulus of the PHAs increased with fiber addition without the use of coupling agents [23]. Similarly, PLA-based composites reinforced with regenerated cellulose (Lyocell), hemp, kenaf, or cotton also present an improvement in tensile strength and Young's modulus without the addition of coupling agents [24].

For all the reinforced samples produced in this study, Young's modulus increases compared to neat polymer films (Table 2), though in some cases without a statistical difference, with the exception of $3 \%$ CNC-PLA samples that exhibit slightly lower stiffness values compared to neat PLA samples. The same positive behavior is observed on the tensile strength of all the reinforced composites, except the samples of PLA reinforced with $30 \%$ of MF. Thus, it is proven that the addition of MF in both types of biopolymer may present a reinforcing effect when adequately formulated.

In tensile tests that used non-woven flax mat PHB composites produced by the film-stacking method with different fiber contents, the stiffness of the composite materials increased with the fiber content [25]. For high fiber contents ( $>30$ vol.\%), flax/PHA composites presented similar elastic modulus to short fiber flax/polypropylene and glass-mat-reinforced thermoplastic composites. Regarding tensile strength, the effect of fiber addition to PHA was not significant, whereas the addition of flax resulted in a lower elongation at ultimate strength of the composites, i.e., approx. $1.5 \%$ for all fiber volume fractions. Thus, the results brought here suggest a favorable application of MF to reinforced PHA matrices in composite products.

\subsection{Differential Scanning Calorimetry}

Differential scanning calorimetry tests were performed to evaluate and compare the effect of the reinforcement addition on the crystallinity of each polymer. Since annealing, i.e., slow cooling after molding, relieves the internal stresses introduced during the film fabrication [26], a thermal treatment consisting of a heating at $80^{\circ} \mathrm{C}$ for $24 \mathrm{~h}$ and later cooling at room temperature was applied before DSC testing. The temperature chosen lies in between the glass transition temperature, $\mathrm{T}_{\mathrm{g}}\left(\sim 60^{\circ} \mathrm{C}\right)$ and the cold crystallization temperature, $\mathrm{T}_{\mathrm{cc}}\left(>100^{\circ} \mathrm{C}\right)$. It has been found that the polymer crystallite morphology can be also modified upon annealing at a temperature higher than the $\mathrm{T}_{\mathrm{g}}$, thus changing 
the physical properties of the polymers [26]. Thermal annealing is a simple route for stabilizing glassy polymers via the densification of their polymer chains. The effects of annealing are depicted on the first DSC heating cycle of the samples (Figure 3a). Since no exothermic peak was observed during cooling, the $\Delta \mathrm{H}_{\mathrm{m}}$ value was used to calculate the $\mathrm{X}_{\mathrm{c}}$ of the PLA/PHA-CNC/MF composites (Table 3). Compared to the neat PHA pellets, pure PHA films after solvent casting undergo a reduction in crystallinity, while the reinforcement of the films leads to higher crystallinity regardless of the type of reinforcement. For low $X_{c}$ values (Table 3) as is the case of PHA samples (8.1\%), the crystalline nature of the reinforcements may lead to an increase in the crystallinity nucleation of the matrix due to a better arrangement of the polymer around the surface of the fillers [27]. Therefore, higher reinforcement contents have a more pronounced effect on polymer crystallinity, since MF addition has a higher impact on the crystallinity of PHA compared with CNC samples. On the other hand, PLA films increase their crystallinity with annealing in comparison with samples without thermal treatment. The addition of the reinforcement reduces the crystallinity of the films for most formulations, although the highest crystallinity is achieved by samples with $10 \% \mathrm{MF}$. A single peak in the melting region of neat PLA (Figure 3a) indicates a homogeneous distribution of ordered crystals. However, the addition of MF in PLA matrices leads to a heterogeneous crystal distribution, evidenced by a two-step melting process.

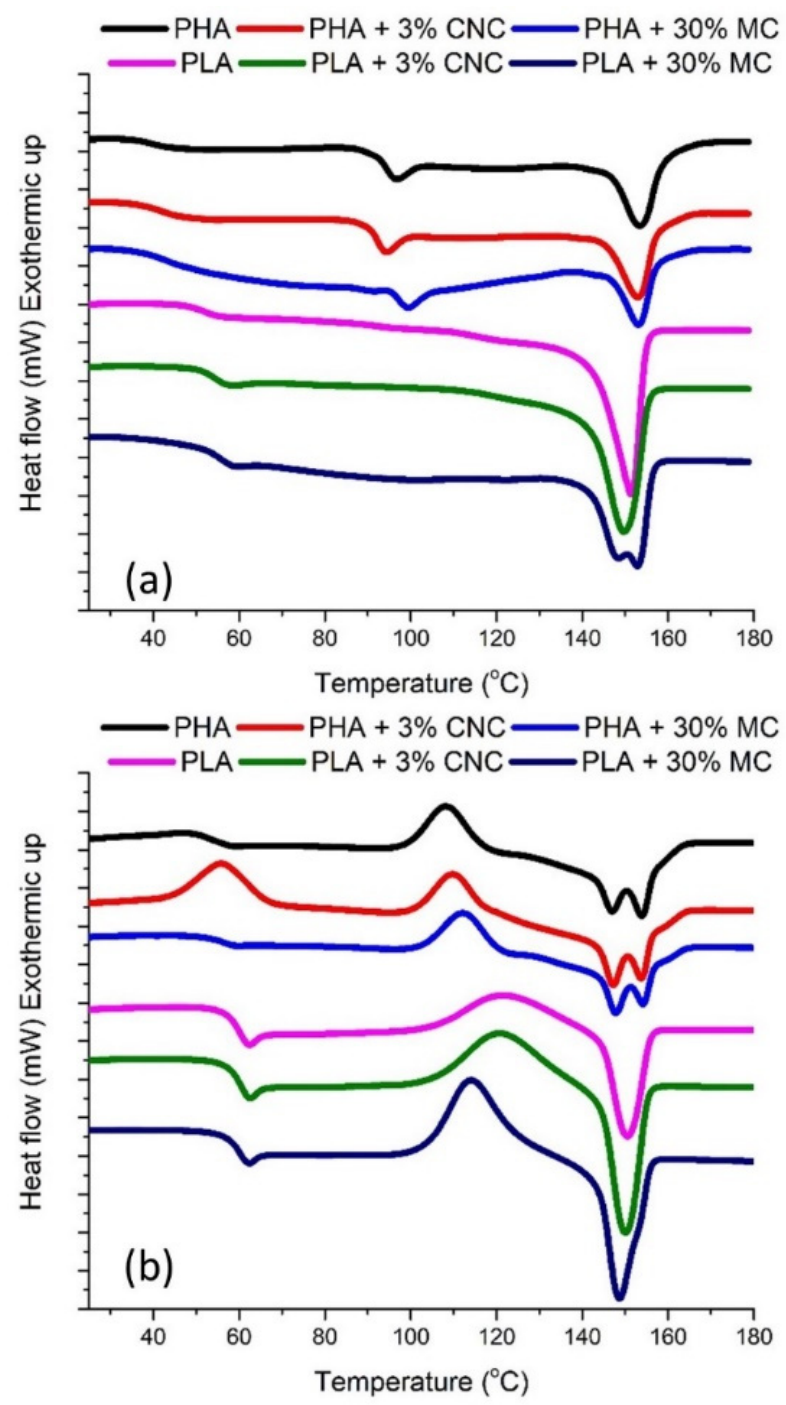

Figure 3. Differential Scanning Calorimetry curves of the PHA and PLA films reinforced with CNC and MF during the first heating stage (a) and during the second heating stage (b). 
Since a second heating step at a rate of $10^{\circ} \mathrm{C} / \mathrm{min}$ was applied after a fast cooling (quenching), the effect of quenching on the crystallinity of the samples is expected to be observed (Figure $3 b$ ). The quenched PLA samples exhibit a strong cold crystallization peak, which is particularly sharp for MF reinforced PLA films. In contrast, PHA samples exhibit a two-step broader low intensity cold crystallization peak compared to the first heating. Thus, quenching leads to a recovery of the crystallinity of PHA samples, to values similar to the initial values before processing (Table 3), and increases $\mathrm{T}_{\mathrm{cc}}$, though a heterogeneous crystal distribution is promoted [28]. These exothermic peaks reveal the presence of a large number of active nuclei. For neat PLA films, quenching reduces crystallinity, but for PLA samples reinforced with MF, particularly for higher concentrations (20 and $30 \%$ ), this fast cooling is translated into a higher crystallinity.

\subsection{Fourier Transformed Infrared Spectroscopy}

In order to assess any possible chemical interaction between the different polymers and the reinforcing filler, FTIR analysis was performed. Regarding PHA samples, the bands in the range 3015-2955 $\mathrm{cm}^{-1}$ are assigned to $-\mathrm{CH}_{3}$ asymmetric stretching vibrations and those in the range $2940-2915 \mathrm{~cm}^{-1}$ to $-\mathrm{CH}_{2}$ asymmetric stretching vibrations [29]. The range from 2885 to $2845 \mathrm{~cm}^{-1}$ is distinctive of symmetric stretching modes of $-\mathrm{CH}_{3}$ and $-\mathrm{CH}_{2}[29,30]$. The peaks at $2976 \mathrm{~cm}^{-1}, 2934 \mathrm{~cm}^{-1}$ and $2874 \mathrm{~cm}^{-1}$ and the shoulder at $2923 \mathrm{~cm}^{-1}$ arise from the crystalline state and that at $2997 \mathrm{~cm}^{-1}$ from the amorphous phase [31,32]. The shoulder at $3007 \mathrm{~cm}^{-1}$, associated to $-\mathrm{CH}_{3}$ asymmetric stretching, points to the presence of intermolecular $\mathrm{CH}-\mathrm{O}$ hydrogen bonds in PHB crystals [29]. Regarding the composites' spectra, little differences may be noticed when composites are reinforced with CNC due to the low concentration of the fillers and, therefore, no chemical modification is perceived in the functional groups. In the case of MF reinforced composites, at $1163 \mathrm{~cm}^{-1}$ there is an increase in intensity that represents the $-\mathrm{C}-\mathrm{O}-\mathrm{C}-$ stretching of the cellulose of the reinforcement [33]. However, additional functional groups are not observed, evidencing a lack of chemical interference.

From the FTIR spectrum of PLA samples (Figure $4 \mathrm{~b}$ ), distinct characteristic FTIR peaks were observed at $866 \mathrm{~cm}^{-1}, 1073 \mathrm{~cm}^{-1}, 1454 \mathrm{~cm}^{-1}, 1742 \mathrm{~cm}^{-1}$ and $2926 \mathrm{~cm}^{-1}$ corresponding to $-\mathrm{C}-\mathrm{O}-\mathrm{C}-$ bond stretching, $-\mathrm{CH}_{3}$ asymmetric vibrations, $-\mathrm{CH}$ bending vibrations, $-\mathrm{C}=\mathrm{O}$ vibrations and $-\mathrm{CH}_{3}$ symmetric vibrations, respectively, for neat PLA films [34]. All these peaks are also present in every PLA-based sample, which indicates that PLA functional groups are not altered with the addition of reinforcing fillers. For the case of $\mathrm{CNCs}$, the peak at $2808 \mathrm{~cm}^{-1}$ represents the $-\mathrm{CH}$ stretching band, peaks at $1163 \mathrm{~cm}^{-1}$ represent the $-\mathrm{C}-\mathrm{O}-\mathrm{C}$ - stretching in $\beta-1,4-\mathrm{D}$ glycosidic linkage present in CNCs and peaks at $1427 \mathrm{~cm}^{-1}$ represent the symmetric $-\mathrm{CH}_{2}$ bending peak [33]. The presence of peaks near $1750 \mathrm{~cm}^{-1}$ in all the composites indicates the presence of free-CO groups. Similarly, the peaks around $1450 \mathrm{~cm}^{-1}$ and $2940 \mathrm{~cm}^{-1}$ in all the nanocomposites represent the symmetric $-\mathrm{CH}_{2}$ bending and stretching vibrations, respectively [33]. It is worth mentioning that the spectrum of MF is similar to $\mathrm{CNC}$, revealing a high cellulose content in the microfibers after their bleaching. 
(a)

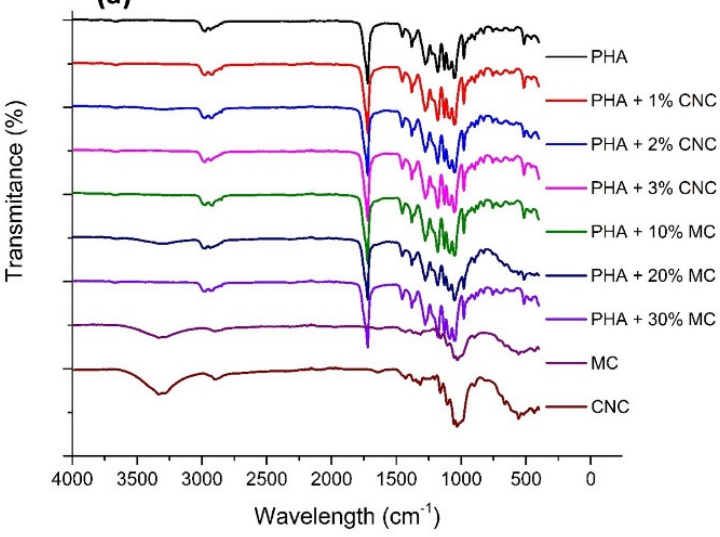

(b)

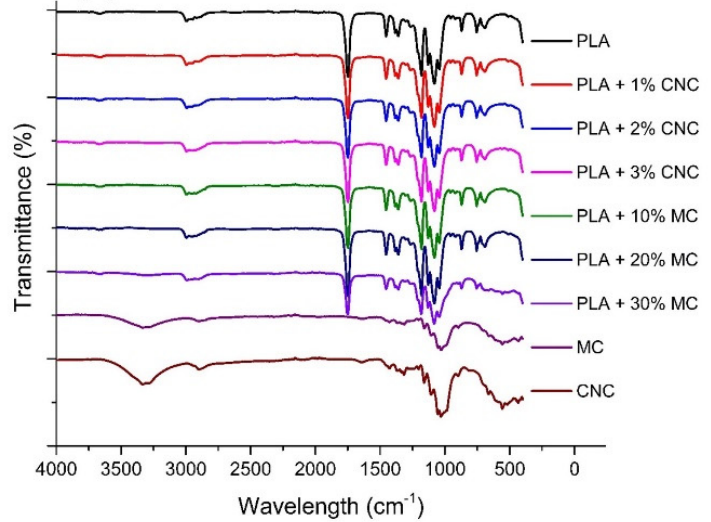

Figure 4. Fourier Transform Infrared spectrograms of the PHA (a) and PLA (b) films reinforced with $\mathrm{CNC}$ and MF.

\subsection{Thermogravimetric Analysis}

Figure 5 shows the thermal degradation with the increase in temperature of each analyzed polymer, reinforcement filler, and composite to assess and compare the influence of the addition of cellulose particles in these polymeric films. Regarding the different types of reinforcement, MF presents a higher peak degradation temperature $\left(357^{\circ} \mathrm{C}\right)$ compared to $\mathrm{CNC}\left(305^{\circ} \mathrm{C}\right)$. This difference may be attributed to a partial lignin content in MF even after their bleaching since lignin undergoes thermal degradation up to $600^{\circ} \mathrm{C}$ [35]. PHA (Figure 5a) exhibits a two-step degradation process, with two clearly defined peaks centered at $275^{\circ} \mathrm{C}$ and $345^{\circ} \mathrm{C}$. The thermal decomposition between $170{ }^{\circ} \mathrm{C}$ and $250{ }^{\circ} \mathrm{C}$ is related to the loss of low molecular weight compounds of the biopolymer [36]. The maximum mass loss of PHA occurs at $275^{\circ} \mathrm{C}$ and is associated with the ester cleavage of the PHA component by elimination reaction [36]. The addition of both $\mathrm{MF}$ and $\mathrm{CNC}$ reinforcement increases the thermal stability of PHA since the mass loss is reduced in the composites at $275^{\circ} \mathrm{C}$. The difference in behavior between MF and $\mathrm{CNC}$ reinforced composites at $345^{\circ} \mathrm{C}$ is related to the mass fraction of MF-based samples, which is 10 times higher than the filler content in CNC-based samples. However, the overall thermal stability is similar for samples reinforced with low MF content (10 wt.\%) compared to CNC samples. In the case of PLA films, pure PLA samples present a single-step decomposition process with a maximum decomposition rate at $375^{\circ} \mathrm{C}$, which takes place at higher temperatures than in the PHA samples $\left(275^{\circ} \mathrm{C}\right)$ and both pure $\mathrm{CNC}\left(305^{\circ} \mathrm{C}\right)$ and $\mathrm{MF}\left(357^{\circ} \mathrm{C}\right)$ (Table 3$)$. The PLA degradation reaction is based on a hydroxyl end-initiated ester interchange process and chain homolysis [37]. Contrary to what is noted for PHA samples, the addition of MF in PLA samples (Figure 5b) reduces the thermal stability of the films by $37 \%$. However, the addition of CNC preserves the thermal stability of the PLA films, since it has little effect in this regard given the low CNC content.

\subsection{Microscopy Analysis}

From Figure $6 \mathrm{a}$, d it can be noted that both PHA and PLA films present a smooth surface with small apparent pores, 22 and $27 \mu \mathrm{m}$, respectively. This apparent porosity is caused by the solvent casting method since during solvent evaporation some air bubbles are entrapped and remain as voids within the solid phase. Despite the porosity of the samples, the neat polymer matrices exhibit conventional mechanical performance compared to the results reported in the literature $[20,21]$. A clear effect of the addition of CNC in both PHA and PLA is the increase in apparent porosity since for PHA samples the number of superficial pores is increased (Figure 6b) and for PLA samples the size of the pores is enlarged (Figure 6e). This rise in apparent porosity leads to higher specific surfaces, which translate into modifications of the hygroscopy of the materials. 

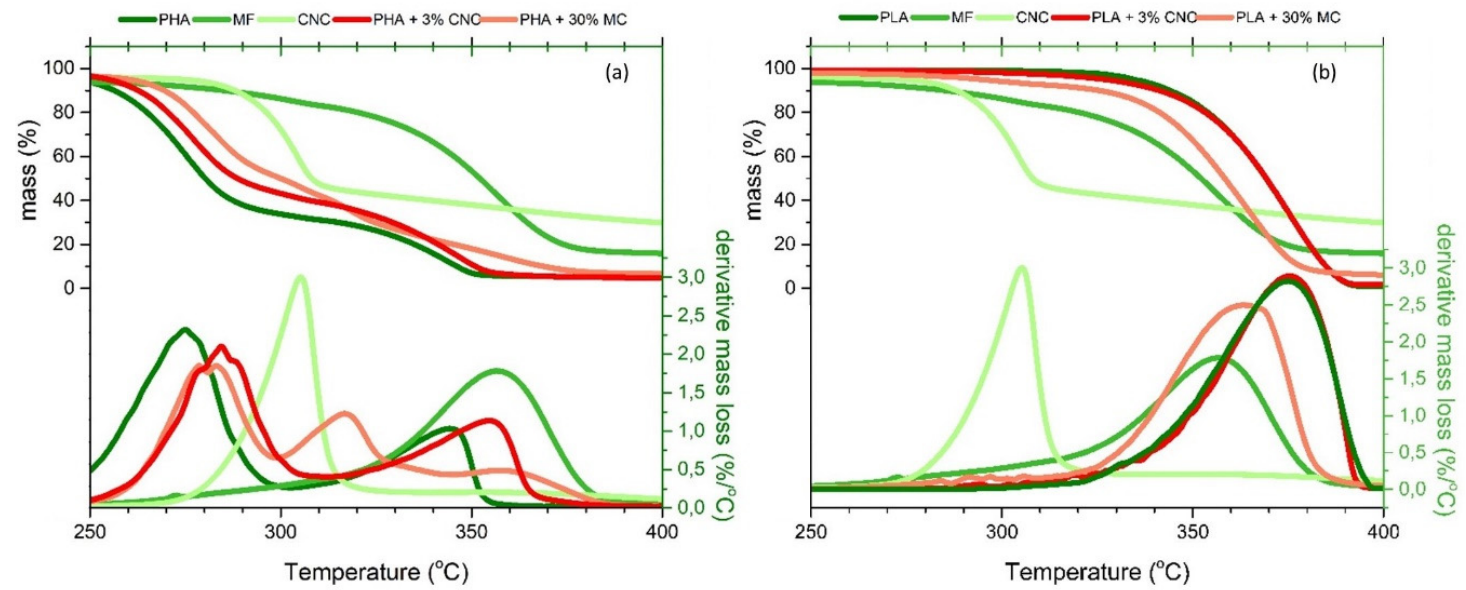

Figure 5. Thermograms and their derivatives of the PHA (a) and PLA (b) films reinforced with CNC and MF.

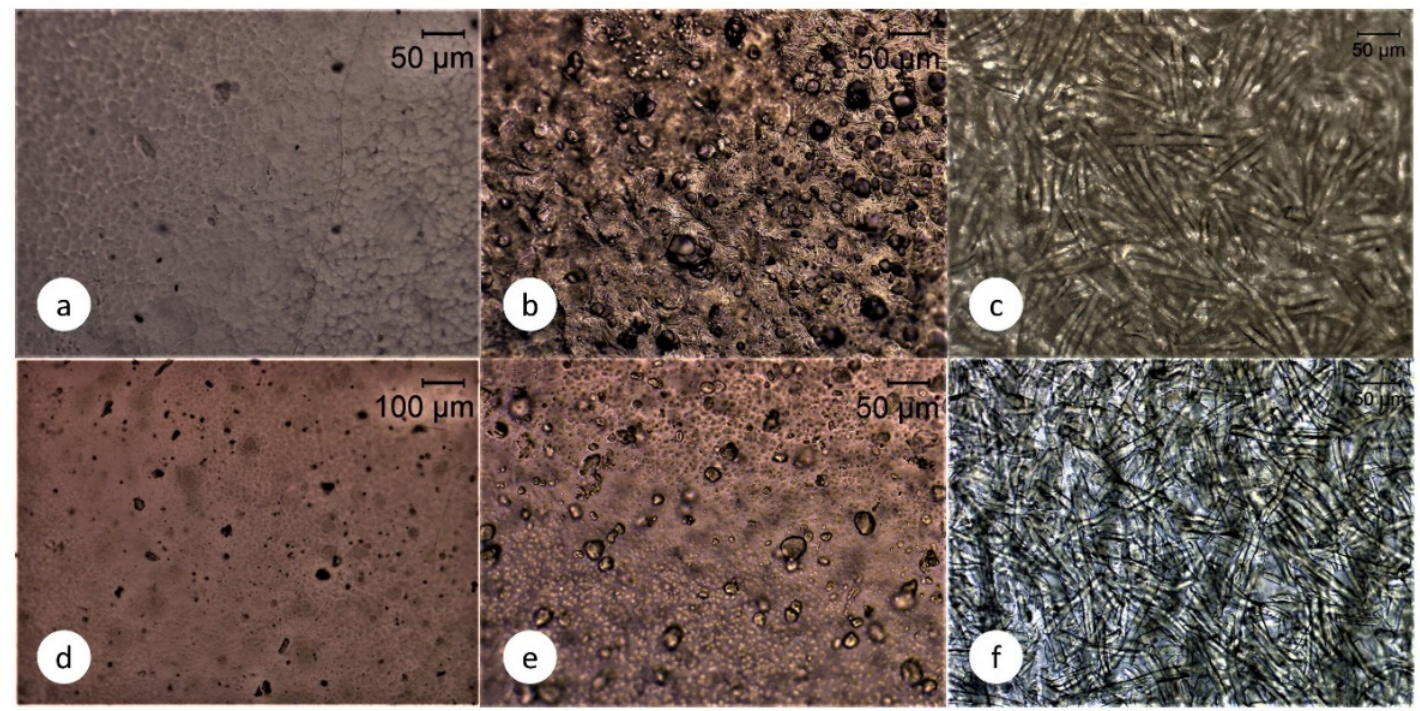

Figure 6. Surface optical micrographs of neat PHA films (a), PHA films reinforced with 2 wt. \% CNC (b), reinforced with 20 wt.\% MF (c), neat PLA (d), PLA films reinforced with 2 wt.\% CNC (e), reinforced with 20 wt. \% MF (f).

Contact angle measurement was conducted to evaluate the wettability of the pristine PHA and PLA film and the nanocomposite films after their combination with different concentrations of $\mathrm{CNC}$ and MF. Contact angle measurements and surface roughness may be related to each other [27]. Contact angle results (Table 3) reveal that the hydrophobicity, and therefore the water barrier properties of the nanocomposite film, are somewhat related to the crystallinity degree of the films, rather than the concentration of fillers. When the $X_{c}$ is compared with the contact angle for every sample after the first heating stage, a higher crystallinity degree leads to higher hydrophobicity for both types of polymer. The increase in crystallinity of PHA films with the addition of both types of reinforcement is also reflected in the increase in the contact angle. It might be explained by the crystalline nature of the reinforcements, which leads to an increase in the hydrophobicity of the matrix, thus increasing the contact angle [27]. Therefore, the water barrier properties of this type of films may be functionalized by thermal treatment according to the desired properties. Thus, when MF is added to both types of biopolymers, PLA and PHA, a more hydrophobic performance may be achieved by film quenching.

In the case of samples reinforced with $\mathrm{MF}$, a rough surface with a dense network of microfibers surrounded by a thin coating of polymer is observed (Figure $6 \mathrm{c}, \mathrm{f})$. The average length of the fibers after 
casting is $332.2 \mu \mathrm{m}$ with an average width value of $11.3 \mu \mathrm{m}$. The length of the fibers decreases during the high-shear mixing process compared to the initial morphological characterization. The increase in apparent porosity is also confirmed by SEM analysis. Figure 7 shows the surface of PHA films with no reinforcement (a), with $1 \% \mathrm{CNC}$ (b) and with $20 \%$ of MF. In spite of reducing the number of apparent pores, it is clear that the addition of $\mathrm{CNC}$ increases the pore size compared to unreinforced PHA, from an average pore size of $2.2 \mu \mathrm{m}$ up to a $7.1 \mu \mathrm{m}$. A similar trend is observed in PLA samples, where apparent pore size increases from $2.7 \mu \mathrm{m}$ up to $8.1 \mu \mathrm{m}$. With the addition of MF, the number of pores remains at the same level as for unreinforced samples, while the average pore size increases up to $3.8 \mu \mathrm{m}$.

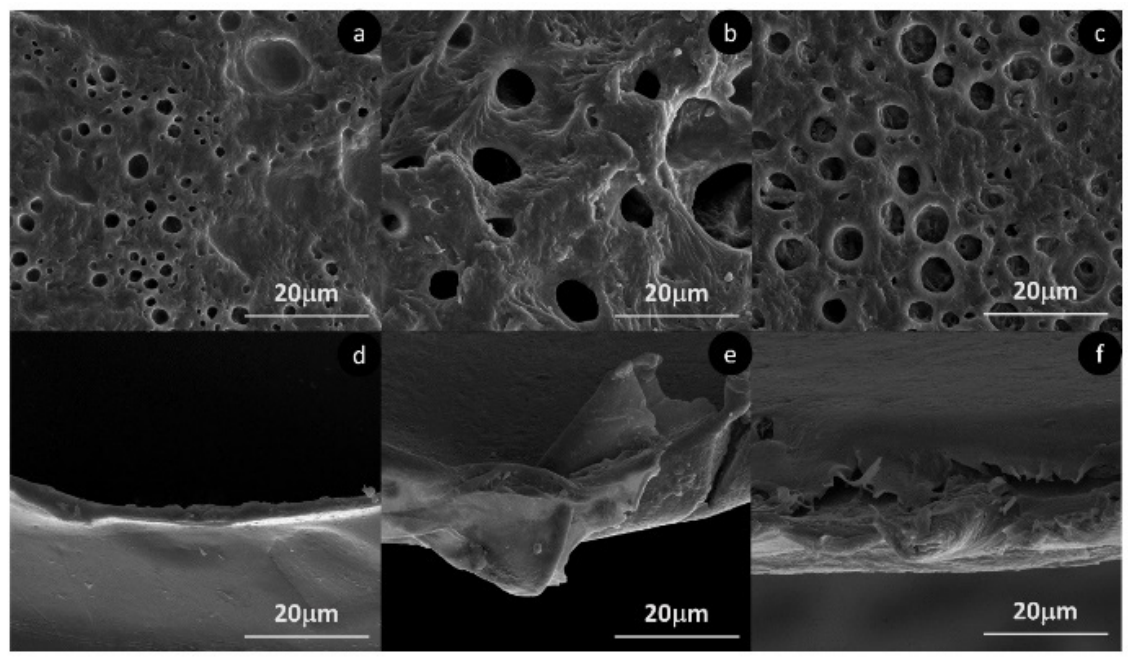

Figure 7. Scanning electron microscope of films surface of neat PHA (a), PHA $+2 \%$ CNC (b), PHA $+20 \%$ MF (c) and fracture surface of neat PLA (d), PLA $+2 \%$ CNC (e) and PLA $+20 \%$ MF (f).

The increase in apparent pore size for PHA is accompanied by an increase in roughness, as is shown by AFM in Figure 8. The different mean roughness values for unreinforced PHA, $1 \%$ CNC and $20 \% \mathrm{MF}$ reinforced samples are $117.7 \mathrm{~nm}, 189.6 \mathrm{~nm}$ and $318.7 \mathrm{~nm}$, respectively. Surface roughness is an essential parameter for multi-layer composites since it may affect the interfacial bonding between the polymer and reinforcement layers. Surface roughness promotes an enhancement of the interfacial adhesion and allows greater stress transfer between the matrix and reinforcements, reducing the capacity of fiber debonding. Therefore, the increase in surface roughness with the addition of MF may benefit the application of this type of material in multi-layer composites.

AFM also confirms the modification of the surface roughness with the addition of fibers for the PLA composite samples (Figure 8). As noted for PHA, in PLA films the roughness is also increased, from $74.4 \mathrm{~nm}$ (plain PLA) up to 88.7 and $174.8 \mathrm{~nm}$ for $1 \% \mathrm{CNC}$ and $20 \% \mathrm{MF}$ samples, respectively. Once again, the gain in roughness is more notorious for samples reinforced with $\mathrm{MF}$, which can be translated into a better interlaminar bonding in multi-layer composite applications. In the case of PLA samples, SEM (Figure 7) reveals that fractured surfaces, even after their necking, are rougher with the addition of different reinforcements. In Figure 7d, a neat PLA sample of around $2 \mu \mathrm{m}$ thickness (cross-section area is around 100 times smaller than the average produced films with $200 \mu \mathrm{m}$ thickness) presents a smooth surface, while Figure 6e,f clearly shows rougher surfaces.

\subsection{Ultraviolet-Visible Spectroscopy}

In the case of UV protective films (UV-PF), the light-resistant capacity of the UV-PF is the main indicator of packaging materials for UV susceptible products. In this study, fiber-reinforced thin transparent films produced by solvent casting were investigated by light transmittance analysis (Figure 9). PLA films showed no UV light transmission in the lower range of UV-C (100-230 nm) 
and started to show transmission (up to 40\%) in the higher range of UV-C (230-280 nm) (Figure 9a). From this point, the transmittance of PLA increases to 90\% for UV-B (280-315 nm) and 315-400 nm (UV-A), which remained constant in the wavelength range of 350-800 nm. The addition of CNC to PLA films has an insignificant effect on the PLA film transmittance in this region. For wavenumbers below $350 \mathrm{~nm}$, the addition of CNC reduces the transmittance by around 5\% for the higher concentration contents (2 and $3 \mathrm{wt}$ \%). In contrast, all PLA-MF composites showed decreased transmittance across all wavelengths. This variation in transmittance is related to the presence of UV-absorbing chromophores in the reinforcing particles of MF. The lignin content of the MF may explain this effect, as observed in the thermogravimetric analysis [35]. Lignin is well known to be UV absorbent because of the presence of UV-absorbing chromophores such as phenolic and ketone groups [38-40]. Therefore, MF-reinforced PLA films were able to absorb UV, and the higher the contents of MF in the film (10, 20 and $30 \mathrm{wt} . \%)$, the higher the UV absorption of the composite, displaying transmittance values of 79.1, 70.3 and $40.3 \%$, respectively.
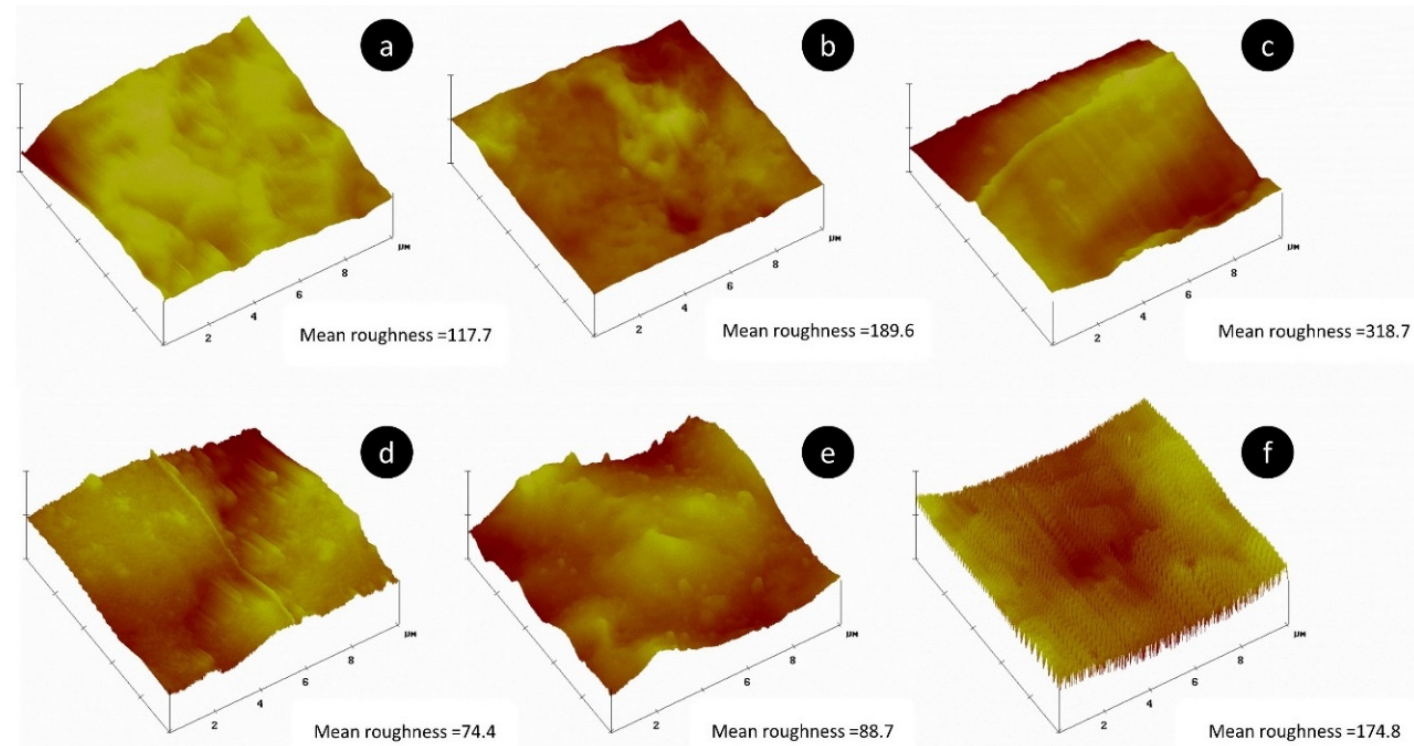

Figure 8. Atomic Force Microscopy height map diagram and mean roughness values of neat PHA (a), PHA $+2 \%$ CNC (b), PHA + 20\% MF (c), neat PLA (d), PLA + 2\% CNC (e) and PLA + 20\% MF (f).
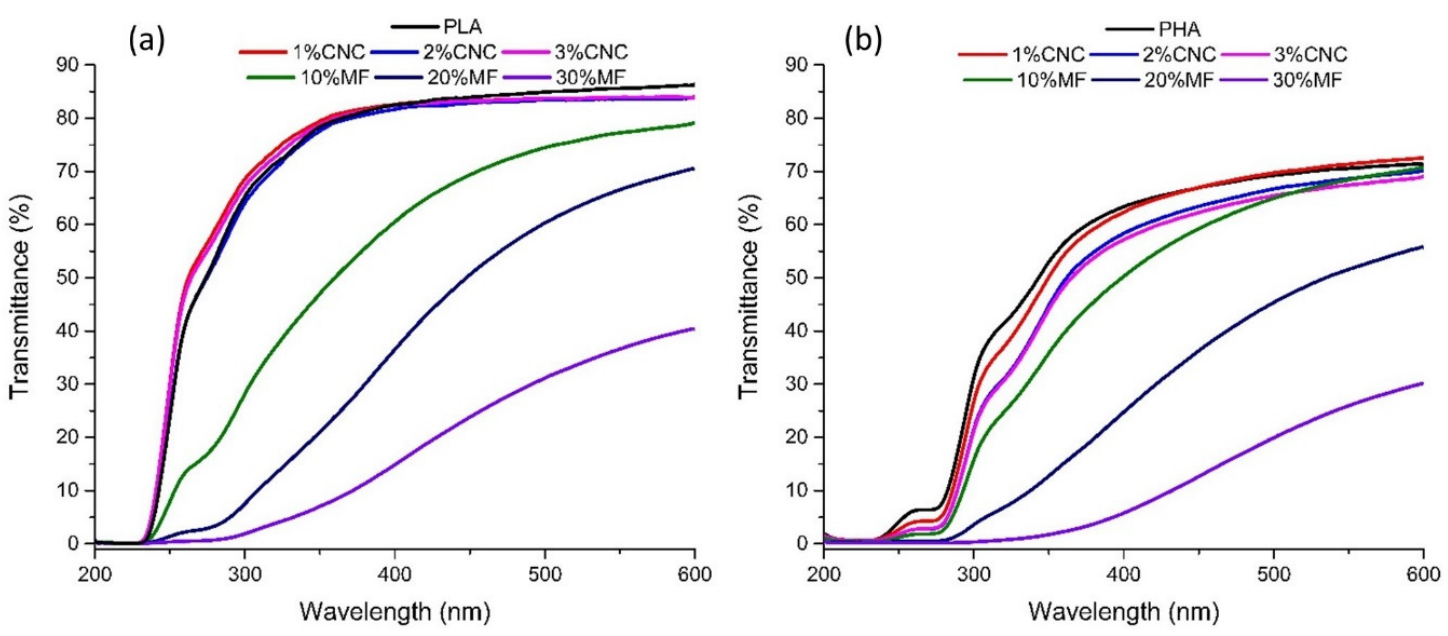

Figure 9. UV-Vis spectrograms of the PHA (a) and PLA (b) films reinforced with CNC and MF.

Regarding neat PHA samples presented in Figure 9b, the transmittance values are lower compared to PLA films, with values of around $70 \%$ at $600 \mathrm{~nm}$. In contrast to PLA films, the addition of high 
concentrations of CNC (2 and 3 wt.\%) in PHA specimens leads to a 15\% decrease in the transmittance through the entire spectrum. The major difference between PHA and PLA films is the improvement in the UV light barrier ability of the PHA films. This UV blocking effect is more pronounced when MF is added, in comparison to samples reinforced with CNC. At $600 \mathrm{~nm}$, when MF is added in different concentrations (10, 20 and $30 \mathrm{wt} . \%)$ in PHA, the transmittance is reduced by 1.1, 33.1 and $244 \%$, respectively. This UV blocking effect is more evident for shorter wavelengths. These results indicate that both PHA and PLA composites reinforced with MF present better UV-protecting properties compared to samples with CNC.

\section{Conclusions}

The addition of MF cellulose-based fibers is presented as an alternative to reinforcing biopolymers films, offering some advantages compared to the addition of CNC. Despite the higher specific surface area of CNC and, therefore, the advantages associated with it, it also reduces the possibility of introducing higher concentrations of this type of filler in composite applications, especially in commodity ones. Moreover, the high production cost of CNC also limits the application of this type of filler for high added value purposes, whereas MF from kraft pulp may help to reduce not only the cost of the filler but the whole composite with the addition of up to $20 \mathrm{wt}$.\% of reinforcement.

Compared to $\mathrm{CNC}, \mathrm{MF}$ have a better reinforcing effect on PHA samples, increasing both tensile strength and Young's modulus. Combined with this improvement of the mechanical performance of PHA films, the addition of MF causes a notorious increase in the roughness of the films, compared to both neat PLA and PHA, and composites reinforced with CNC. This added roughness may have interesting applications in multi-layer composites where improved interlaminar bonding is required. Moreover, the surface affinity of the films to water may be controlled by the addition of MF and specific cooling conditions since the crystallinity degree of the film is related to the contact angle with water. In addition, the use of MF as reinforcement in biopolymer films may be applied in UV-blocking elements since MF clearly diminishes UV-VIS transmittance in the whole wavelength range.

After this overall characterization of biopolymer films reinforced with MF, a more in-depth characterization should be addressed in order to better understand the performance of this type of reinforcement for specific applications. Considering the benefits of both types of reinforcements explored here, $\mathrm{CNC}$ and MF, a possible hierarchical reinforcement can be conducted to understand their synergic effect on the properties of this type of composite. Moreover, possible treatments on cellulose fibers would introduce additional functionalities and improved properties to bio-based composites.

Along with the improved mechanical properties of the biopolymers evaluated in this work with the addition of MF, the use of MF brings an important economic advantage. This reduction in cost is related to the price of this type of filler. In this work, the authors used commercial kraft paper to avoid any heterogeneity in the quality of the microfibers and, therefore, to obtain consistent films. Even using this high-quality raw material, the price of the filler is much cheaper compared with PHA. Then, this filler, when dosed at $30 \mathrm{wt}$ \% , clearly reduces the cost of the polymer composite. However, the great advantage of using MF is the possibility of reusing recycled kraft paper once is discarded from its initial purpose. Recycled kraft paper from a selective waste collection after its processing could be up to 10 times cheaper than technical grade kraft paper.

It is remarkable that the defibrillation process applied in this study only involves immersion in water, low-energy mechanical stirring and drying. In the end, in industrial processes, up to $90 \%$ of the energy demand of this process is due to water evaporation. Using efficient drying procedures such as Through Air Drying (TAD), water removal involves $4800 \mathrm{~kJ} / \mathrm{kg}$ of water evaporated [41]. This requires around $695 \mathrm{kWh}$ to obtain a ton of dried microfibers. In addition, the water required in this process could be used in a loop cycle after decontamination (impurities, oil and pigments) through straightforward flocculation/filtration techniques.

Author Contributions: Conceptualization, G.M. and R.F.; methodology, G.M.; validation, G.M., C.G. and R.F.; formal analysis, G.M.; investigation, G.M.; resources, R.F.; data curation, C.G.; writing—original draft preparation, 
G.M.; writing-review and editing, C.G.; visualization, G.M.; supervision, R.F.; project administration, R.F.; funding acquisition, R.F. All authors have read and agreed to the published version of the manuscript.

Funding: This research was funded by TSSiPRO; NORTE-01-0145-FEDER-000015-project, Technologies for Sustainable and Smart Innovative Products, which involves this research work and financed by the European Regional Development Fund (ERDF) through the Support System for Scientific and Technological Research (Structured R \& D \& I Projects) of the Regional Operational Program for Northern Portugal 2020.

Conflicts of Interest: The authors declare no conflict of interest.

\section{References}

1. Shekar, H.S.; Ramachandra, M. Green composites: A review. Mater. Today Proc. 2018, 5, 2518-2526. [CrossRef]

2. Ramesh, M.; Palanikumar, K.; Reddy, K.H. Plant fibre based bio-composites: Sustainable and renewable green materials. Renew. Sustain. Energy Rev. 2017, 79, 558-584. [CrossRef]

3. Christian, S.; Billington, S.L. Mechanical response of PHB and cellulose acetate natural fiber-reinforced composites for construction applications. Compos. Part B Eng. 2011, 42, 1920-1928. [CrossRef]

4. Zhang, Q.; Shi, L.; Nie, J.; Wang, H.; Yang, D. Study on poly (lactic acid)/natural fibers composites. J. Appl. Polym. Sci. 2012, 125, E526-E533. [CrossRef]

5. Saba, N.; Jawaid, M.; Al-Othman, O. An overview on polylactic acid, its cellulosic composites and applications. Curr. Org. Synth. 2017, 14, 156-170. [CrossRef]

6. Mathuriya, A.S.; Yakhmi, J.V.; Martínez, L.M.T.; Kharissova, O.V.; Kharisov, B.I. Polyhydroxyalkanoates: Biodegradable plastics and their applications. In Handbook of Ecomaterials; Springer: Cham, Switzerland, 2017; pp. 1-29.

7. Bugnicourt, E.; Cinelli, P.; Lazzeri, A.; Alvarez, V. Polyhydroxyalkanoate (PHA): Review of synthesis, characteristics, processing and potential applications in packaging. Express Polym. Lett. 2014, 8, 791-808. [CrossRef]

8. Chen, G.-Q.; Chen, X.-Y.; Wu, F.-Q.; Chen, J.-C. Polyhydroxyalkanoates (PHA) toward cost competitiveness and functionality. Adv. Ind. Eng. Polym. Res. 2020, 3, 1-7. [CrossRef]

9. Koay, S.C.; Yeng, C.M.; May, C.P.; Yeow, T.K.; Kiat, O.T.; How, C.K. Effect of coupling agent content on properties of composites made from polylactic acid and chrysanthemum waste. J. Vinyl Addit. Technol. 2019, 26, 10-16. [CrossRef]

10. Seggiani, M.; Cinelli, P.; Verstichel, S.; Puccini, M.; Vitolo, S.; Anguillesi, I.; Lazzeri, A. Development of fibres-reinforced biodegradable composites. Chem. Eng. Trans. 2015, 1813-1818. [CrossRef]

11. Nery, T.B.R.; Dos Santos, Z.I.G.; José, N.M. Desenvolvimento e caracterização de biocompósitos de polihidroxibutirato e fibra de bananeira. Matéria Rio Jan. 2018, 23. [CrossRef]

12. Machado, M.L.C.; Pereira, N.C.; De Miranda, L.F.; Terence, M.C.; Pradella, J.G.C. Estudo das propriedades mecânicas e térmicas do polímero Poli-3-hidroxibutirato (PHB) e de compósitos PHB/pó de madeira. Polímeros 2010, 20, 65-71. [CrossRef]

13. Shojaeiarani, J.; Bajwa, D. Functionalized Cellulose Nanocrystals for Improving the Mechanical Properties of Poly (Lactic Acid); American Society of Mechanical Engineers: Pittsburgh, PA, USA, 2018; Volume 12.

14. Mokhena, T.C.; Sefadi, J.S.; Sadiku, E.; John, M.J.; Mochane, M.J.; Mtibe, A. Thermoplastic processing of PLA/cellulose nanomaterials composites. Polymers 2018, 10, 1363. [CrossRef] [PubMed]

15. Zheng, T.; Zhang, Z.; Shukla, S.; Agnihotri, S.; Clemons, C.M.; Pilla, S. PHBV-graft-GMA via reactive extrusion and its use in PHBV/nanocellulose crystal composites. Carbohydr. Polym. 2019, 205, 27-34. [CrossRef] [PubMed]

16. Patrício, P.S.D.O.; Pereira, F.V.; Dos Santos, M.C.; De Souza, P.P.; Roa, J.P.B.; Orefice, R.L. Increasing the elongation at break of polyhydroxybutyrate biopolymer: Effect of cellulose nanowhiskers on mechanical and thermal properties. J. Appl. Polym. Sci. 2012, 127, 3613-3621. [CrossRef]

17. Trache, D.; Hussin, M.H.; Haafiz, M.K.M.; Mishra, Y.K. Recent progress in cellulose nanocrystals: Sources and production. Nanoscale 2017, 9, 1763-1786. [CrossRef] [PubMed]

18. Seoane, I.T.; Manfredi, L.B.; Cyras, V.P.; Torre, L.; Fortunati, E.; Puglia, D. Effect of cellulose nanocrystals and bacterial cellulose on disintegrability in composting conditions of plasticized PHB nanocomposites. Polymers 2017, 9, 561. [CrossRef] 
19. Rigotti, D.; Checchetto, R.; Tarter, S.; Caretti, D.; Rizzuto, M.; Fambri, L.; Pegoretti, A. Polylactic acid-lauryl functionalized nanocellulose nanocomposites: Microstructural, thermo-mechanical and gas transport properties. Express Polym. Lett. 2019, 13, 858-876. [CrossRef]

20. Deetuam, C.; Samthong, C.; Choksriwichit, S.; Somwangthanaroj, A. Isothermal cold crystallization kinetics and properties of thermoformed poly (lactic acid) composites: Effects of talc, calcium carbonate, cassava starch and silane coupling agents. Iran. Polym. J. 2020, 29, 103-116. [CrossRef]

21. Singh, M.; Kumar, P.; Ray, S.; Kalia, V.C. Challenges and opportunities for customizing polyhydroxyalkanoates. Indian J. Microbiol. 2015, 55, 235-249. [CrossRef]

22. Oksman, K.; Skrifvars, M.; Selin, J.-F. Natural fibres as reinforcement in polylactic acid (PLA) composites. Compos. Sci. Technol. 2003, 63, 1317-1324. [CrossRef]

23. Torres-Tello, E.V.; Robledo-Ortíz, J.R.; González-García, Y.; Pérez-Fonseca, A.A.; Jasso-Gastinel, C.F.; Mendizábal, E. Effect of agave fiber content in the thermal and mechanical properties of green composites based on polyhydroxybutyrate or poly (hydroxybutyrate-co-hydroxyvalerate). Ind. Crops Prod. 2017, 99, 117-125. [CrossRef]

24. Graupner, N.; Herrmann, A.S.; Müssig, J. Natural and man-made cellulose fibre-reinforced poly (lactic acid) (PLA) composites: An overview about mechanical characteristics and application areas. Compos. Part A Appl. Sci. Manuf. 2009, 40, 810-821. [CrossRef]

25. Barkoula, N.; Garkhail, S.; Peijs, T. Biodegradable composites based on flax/polyhydroxybutyrate and its copolymer with hydroxyvalerate. Ind. Crops Prod. 2010, 31, 34-42. [CrossRef]

26. Di Vona, M.L. Annealing of polymer membranes. In Encyclopedia of Membranes; Drioli, E., Giorno, L., Eds.; Springer: Berlin/Heidelberg, Germany, 2014; pp. 1-2.

27. Kumar, R.; Kumari, S.; Rai, B.; Das, R.; Kumar, G. Effect of nano-cellulosic fiber on mechanical and barrier properties of polylactic acid (PLA) green nanocomposite film. Mater. Res. Express 2019, 6, 125108. [CrossRef]

28. Gupta, A.; Simmons, W.; Schueneman, G.T.; Hylton, D.; Mintz, E.A. Rheological and thermo-mechanical properties of poly (lactic acid)/lignin-coated cellulose nanocrystal composites. ACS Sustain. Chem. Eng. 2017, 5, 1711-1720. [CrossRef]

29. Sato, H.; Murakami, R.; Padermshoke, A.; Hirose, F.; Senda, K.; Noda, I.; Ozaki, Y. Infrared spectroscopy studies of $\mathrm{CH} \cdots \mathrm{O}$ hydrogen bondings and thermal behavior of biodegradable poly (hydroxyalkanoate). Macromolecules 2004, 37, 7203-7213. [CrossRef]

30. Socrates, G. Infrared and Raman Characteristic Group Frequencies: Tables and Charts, 3rd ed.; Wiley: Chichester, UK, 2010.

31. Zhang, J.; Sato, H.; Noda, I.; Ozaki, Y. Conformation rearrangement and molecular dynamics of poly (3-hydroxybutyrate) during the melt-crystallization process investigated by infrared and two-dimensional infrared correlation spectroscopy. Macromolecules 2005, 38, 4274-4281. [CrossRef]

32. Padermshoke, A.; Katsumoto, Y.; Sato, H.; Ekgasit, S.; Noda, I.; Ozaki, Y. Melting behavior of poly (3-hydroxybutyrate) investigated by two-dimensional infrared correlation spectroscopy. Spectrochim. Acta Part A Mol. Biomol. Spectrosc. 2005, 61, 541-550. [CrossRef]

33. Brizuela, A.B.; Bichara, L.C.; Romano, E.; Yurquina, A.; Locatelli, S.; Brandán, S.A. A complete characterization of the vibrational spectra of sucrose. Carbohydr. Res. 2012, 361, 212-218. [CrossRef]

34. Borkotoky, S.S.; Dhar, P.; Katiyar, V. Biodegradable poly (lactic acid)/Cellulose nanocrystals (CNCs) composite microcellular foam: Effect of nanofillers on foam cellular morphology, thermal and wettability behavior. Int. J. Biol. Macromol. 2018, 106, 433-446. [CrossRef]

35. Bai, J.; Chen, X.; Shao, J.; Jia, C.; Wang, Q. Study of breakage of main covalent bonds during co-pyrolysis of oil shale and alkaline lignin by TG-FTIR integrated analysis. J. Energy Inst. 2019, 92, 512-522. [CrossRef]

36. Ojha, N.; Das, N.; Ojhaa, N. A Statistical approach to optimize the production of Polyhydroxyalkanoates from Wickerhamomyces anomalus VIT-NN01 using response surface methodology. Int. J. Biol. Macromol. 2018, 107, 2157-2170. [CrossRef] [PubMed]

37. Zou, H.; Yi, C.; Wang, L.; Liu, H.; Xu, W. Thermal degradation of poly (lactic acid) measured by thermogravimetry coupled to Fourier transform infrared spectroscopy. J. Therm. Anal. Calorim. 2009, 97, 929-935. [CrossRef]

38. Lanzalunga, O.; Bietti, M. Photo and radiation chemical induced degradation of lignin model compounds. J. Photochem. Photobiol. B Biol. 2000, 56, 85-108. [CrossRef] 
39. Park, S.Y.; Kim, J.-Y.; Youn, H.J.; Choi, J.W. Utilization of lignin fractions in UV resistant lignin-PLA biocomposites via lignin-lactide grafting. Int. J. Biol. Macromol. 2019, 138, 1029-1034. [CrossRef]

40. Qian, Y.; Qiu, X.; Zhu, S. Lignin: A nature-inspired sun blocker for broad-spectrum sunscreens. Green Chem. 2015, 17, 320-324. [CrossRef]

41. Stenström, S. Drying of paper: A review 2000-2018. Dry. Technol. 2019, 38, 825-845. [CrossRef]

Sample Availability: Samples of the compounds made out of PHA and PLA are available from the authors.

(C) 2020 by the authors. Licensee MDPI, Basel, Switzerland. This article is an open access article distributed under the terms and conditions of the Creative Commons Attribution (CC BY) license (http://creativecommons.org/licenses/by/4.0/). 